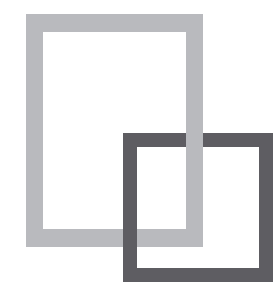

\title{
ZESTAWIENIE ELEMENTÓW ZABYTKOWYCH JAKO NARZĘDZIE WALORYZACJI ZABYTKU W PROCESIE KLASYFIKACJI I KATEGORYZACJI
}

List of historic elements as a tool for valorization of a monument in the process of classification and categorization

\section{Piotr M. Stepien *}

Od dłuższego czasu dyskutowana jest potrzeba kategoryzacji i klasyfikacji zabytków jako narzędzi w metodyce ochrony dziedzictwa historycznego (lub szerzej kulturowego), stąd obecna konferencja. Z naszej codziennej pracy wiemy doskonale, że zabytki są różnorodne, coraz bardziej różnorodne wraz z poszerzaniem się pola ochrony, mają indywidualne cechy - tak jak ludzie.

Czy mają różną wartość?

Choć formalnie nadal obowiązuje zasada „równocenności” - intuicyjnie odczuwamy, że tak, że ich wartość jest różna. Utrata jednej kamienicy w zespole miejskim nie degraduje całkowicie tego zespołu, tym bardziej nie jest szczególnie dotkliwa w skali dziedzictwa narodowego czy światowego. Utrata takich zabytków jak Wawel czy Łazienki byłaby bardzo dotkliwa, dlatego tyle wysiłku włożono w uratowanie i jednego i drugiego zespołu zabytkowego zaliczonego do „najcenniejszych”. Ale podobnie jak w odniesieniu do ludzi, do społeczeństwa - w odniesieniu do zabytków trzeba być bardzo ostrożnym w ogłaszaniu „różnocenności” jako zasady. W społeczeństwie akceptujemy przywileje pewnych osób, pełniących ważne funkcje, natomiast nie akceptujemy deprecjacji innych. Dlatego w pełni podzielam pogląd przedstawiony na obecnej konferencji przez Pana Profesora Szmygina - klasyfikacja zabytków nie może polegać na deprecjonowaniu pewnych grup zabytków, może i powinna polegać na objęciu szczególną ochroną, niejako uprzywilejowaniu, zabytków szczególnie cennych. Utrata całej kategorii zabytków spowodowana zaliczeniem w klasyfikacji do „mało cennych”, „mało wartościowych” - zuboży dziedzictwo podobnie, czy niemal podobnie jak utrata któregoś z najcenniejszych zabytków.

Uważam za uprawnione stwierdzenie, że na równi z poczuciem potrzeby nowych narzędzi w metodyce ochrony zabytków, potrzeby metody na uporządkowanie, na ogarnięcie tej różnorodności zabytków - w naszym środowisku silne są obawy przed negatywnymi skutkami jakie może przynieść źle pojęta i źle przeprowadzona kategoryzacja i klasyfikacja, właśnie taka deprecjonująca. Czarny scenariusz może być następujący: wydane zostaje zarządzenie, rozporządzenie lub inny akt prawny o kategoryzacji i klasyfikacji, no to szybko, pomiędzy natłokiem codziennych spraw, wniosków o pozwolenia, nadzorów autorskich do uzgodnienia, zgłoszeń, narad i konsultacji - wrzucamy teczki zabytków do jakichś tam „szufladek”, bo trzeba zrealizować zarządzenie. Przynajmniej część naszego środowiska tego właśnie - obawia się. 
Dlatego stawiam - stawiam pod dyskusję - tezę (organizatorzy prosili o jasne formułowanie tez): kategoryzacja i klasyfikacja zabytków sa potrzebne, ale spełnia pożyteczna rolę tylko wówczas, gdy będą końcowym etapem rozpoznawania wartości zasobu zabytków, a nie początkowym.

I tutaj przypomnienie sprawy oczywistej, ale oczywiste sprawy trzeba przypominać: dobre rozpoznanie wartości całego zasobu można uzyskać tylko dysponujac dobrym rozpoznaniem wartości każdego ze składników zasobu, czyli poszczególnych zabytków.

Kolejna teza jest następująca:

W pierwszej kolejności należy możliwie precyzyjnie zdefiniować i opisać wartości zabytku, uzasadniając $w$ ten sposób dlaczego go chronimy $i$ co $w$ nim chronimy, a dopiero $w$ dalszej perspektywie można ostrożnie próbować oceniać te wartości w jakiejś skali i porównywać je w obrębie kategorii czy całego zasobu, tworzac klasyfikacje - lub grupować obiekty tworzac kategoryzacje.

Bez naprawdę dobrego, wnikliwego i obszernego opisu wartości zabytku wszelkie „skalowanie” tych wartości i grupowanie, kategoryzowanie - może być nie tylko bezużyteczne, ale nawet szkodliwe. Obsesja rangowania w systemie myślenia techno-ekonomicznego, prowadząca do rangowania bez obiektywnych podstaw, została poddana krytyce przez Neila Postmana w Technopolu już w 1992 r., prawie ćwierć wieku temu, pokolenie temu - nie rozwijam tego wątku, odsyłam do lektury tej znakomitej książki, jest dostępna także w polskim tłumaczeniu. ${ }^{1}$

Opracowanie nowoczesnej metodyki opisu wartości zabytku nie jest oczywiście możliwe w ramach jednego referatu ani nawet konferencji. Oprócz postawienia powyższych, ogólnych tez moim zamiarem (zaznaczonym w tytule) jest przypomnienie o narzędziu, jakie zostało wypracowane w latach 70. i 80. XX wieku i które może być - przy odpowiednim rozwinięciu - istotnym elementem takiej metodyki opisu wartości. Narzędziem tym jest zestawienie elementów zabytkowych obiektu, niesłusznie nieco zapomniane, a w mojej opinii bardzo przydatne.

Dobrze sporządzone zestawienie daje informację o stopniu zachowania substancji zabytkowej i charakterze obiektu, a także o potrzebnym zakresie ochrony. Przypomnieć warto, że „elementem zabytkowym" jest nie tylko fizyczny fragment substancji zabytkowej (ściana, sklepienie, strop, detal, dekoracja itd.), ale także te składniki formy zabytku, które mają charakter historyczny, nawet jeśli materia je tworząca została wymieniona (np. układ pomieszczeń, forma dachu, rodzaj pokrycia itp.). Zestawienie takie można dalej rozbudować, według rodzajów autentyzmu zdefiniowanych przez prof. Olgierda Czernera ${ }^{2}$ - oprócz formy i materiału: technologia, funkcja, oddziaływania i skojarzenia, tworząc zestawienie wartości zabytkowych obiektu.

Jeśli określimy znaczenie poszczególnych elementów (znów raczej opisowo niż cyfrowo!) to przy odpowiednim ustandaryzowaniu takie zestawienia byłyby obiektywną podstawą waloryzacji obiektu zabytkowego, a następnie kategoryzacji i klasyfikacji zasobu, a przede wszystkim określenia formy,

1 PostmanNeil, Technopoly: the Surrender of Culture to Technology, Knopf, New York 1992; wydania polskie: Technopol: Triumf techniki nad kultura, przeł. A. Tanalska-Dulęba, Warszawa: PIW 1995, s. 248; wyd 2 Warszawa 2004, Wyd. Muza, ISBN 83-7200-637-7

2 Czerner Olgierd, Wartość autentyzmu w zabytkach, Ochrona Zabytków 1974, nr 3, s. 180-183 
zakresu i kierunku ochrony danego zabytku - co w mojej opinii jest najważniejsze.

Kilkanaście lat temu, na konferencji „Kraków 2000” mówiłem o potrzebie zdefiniowania różnych form (teraz powiedziałbym raczej: zakresów) ochrony obiektów architektonicznych, na wzór ochrony przyrodniczej, proponując następujące rozróżnienie:

- pełna ochrona konserwatorska (zabytek „kwalifikowany”), ściśle odpowiadająca zasadom Karty Weneckiej, z maksymalnym zachowaniem formy i substancji (autentycznej materii zabytku);

- ochrona architektoniczna tj. przede wszystkim ochrona istotnych cech architektonicznych obiektu (zewnętrznych i wewnętrznych), w mniejszym stopniu jego materii, z dopuszczeniem adaptacji i modernizacji;

- ochrona urbanistyczna i krajobrazowa tj. ochrona zewnętrznych cech obiektu, istotnych dla większego zespołu, bez limitowania (lub z niewielkim limitowaniem) zmian wewnętrznych. ${ }^{3}$

Mając dobrze rozpoznane i opisane wartości zabytku możemy przypisać mu jedną ze zdefiniowanych wyżej form ochrony, co także jest rodzajem klasyfikacji. Być może proponowana skala zakresów ochrony powinna być rozbudowana. Praktyka wskazuje, że trzeba założyć możliwość określania różnych zakresów ochrony dla wydzielonych, jasno określonych części zabytku.

Tu użyję cytatu z tego referatu z 2000 roku:

W tej lub innej klasyfikacji nie może być natomiast stopniowana skuteczność ochrony: szerszy lub węższy zakres ochrony musi być egzekwowany z taką samą konsekwencją i z takimi samymi rygorami prawnymi.

Klasyfikacja obiektów chronionych w zależności od zakresu ochrony (czyli jednocześnie zakresu dopuszczalnej ingerencji) nie jest nowością - od dawna jest stosowana w ochronie środowiska naturalnego: ścisły rezerwat - park narodowy - park krajobrazowy - „otulina” parku. Dzięki temu zasady ochrony przyrodniczej są zrozumiałe dla szerokich kręgów społecznych. Wprowadzenie podobnego stopniowania zakresów ochrony wobec dziedzictwa kulturowego - przy obecnym, szerokim rozumieniu jego zasobów - jest w mojej opinii potrzebne nie tylko dla specjalistów, jako narzędzie metodologicznej, ale także w tym celu, aby zasady tej ochrony były czytelne dla ogółu społeczeństwa. Bez współdziałania całego społeczeństwa, opartego na zrozumieniu zasad ochrony dziedzictwa, nie osiągniemy celu.

Sądzę, że powyższe propozycje sprzed kilkunastu lat - są nadal aktualne i przedkładam je ponownie do dyskusji.

Stępień Piotr M., Klasyfikacja zabytków architektury - propozycja nowej formuly, materiały Międzynarodowej Konferencji Konserwatorskiej Kraków 2000, s.283-284, ISBN 83-7242-174-9 
